\title{
ESTUDO DE CASO DA PORCENTAGEM DE EXTRAÇÃO DE CALDO DE CANA-DE-AÇÚCAR NO PROCESSO DE MOAGEM EM UMA USINA
}

André Luís Kazuo Kanada, Gabriela Fernandez Zanotto, João Antonio Vechi Gasques, Leila Mara Oliveira Cruz, Andréia de Menezes Olivo.

Universidade do Oeste Paulista - UNOESTE, Faculdade de Engenharia "Conselheiro Algacyr Munhoz Maéder", Engenharia de Produção, Presidente Prudente, SP. E-mail: andrekanada@gmail.com.

\section{RESUMO}

Devido à competitividade no mercado atual é notável a necessidade de empresas garantirem a qualidade dos seus produtos e processos produtivos a fim de atender as necessidades dos clientes. Este estudo de caso tem por objetivo utilizar as ferramentas da qualidade para identificar as causas de um baixo nível de extração do caldo da cana-de-açúcar no processo de moagem em uma usina de açúcar e álcool, para auxiliar na melhoria do processo. A metodologia utilizada neste trabalho consiste na abordagem qualitativa, que foi realizada por meio de uma coleta de dados na empresa em estudo. Com a pesquisa foi possível descrever a aplicação de algumas ferramentas da qualidade sob a perspectiva do setor de moagem da usina para sugerir possíveis formas de amenizar ou eliminar causas do problema estudado, de acordo com análise de resultados obtidos.

Palavras-chave: Qualidade, ferramentas da qualidade, baixos níveis de extração, cana-de-açúcar, moagem.

\section{CASE STUDY OF THE PERCENTAGE OF EXTRACTION OF SUGAR CANE BROTH IN THE PROCESS OF MILLING IN A POWER PLANT}

\begin{abstract}
Due to the competitiveness in the current market it is remarkable the need for companies to guarantee the quality of their products and production processes in order to meet the needs of the customers. This case study aims to use the quality tools to identify the causes of a low level of extraction of the sugarcane broth in the process of milling in a sugar and alcohol power plant to assist in the improvement of the process. The methodology used in this work consists of the qualitative approach, which was performed through a data collection in the company under study. With the research, it was possible to describe the application of some quality from the perspective of the milling sector of the power plant to suggest possible ways to reduce or eliminate causes of the studied problem, according to the analysis of results obtained.
\end{abstract}

Keywords: Quality, quality tools, low extraction levels, sugarcane, milling. 


\section{INTRODUÇÃO}

A qualidade é vista atualmente no meio empresarial como um dos principais fatores estratégicos para a competitividade e melhoria de produtividade, proporcionando vantagens às organizações, como a redução de retrabalhos nas linhas de produção, o melhor atendimento dos requisitos dos clientes quanto aos produtos e serviços e a redução de custos pela minimização de desperdícios, segundo Carpinetti (2016).

O conceito da qualidade pode ser definido de inúmeras formas, geralmente relaciona-se o termo qualidade com alguma característica que julgamos ser boa, ou até mesmo desejável, para determinado produto ou serviço (MONTGOMERY, 2004). De acordo com Carpinetti (2016) para algumas pessoas a qualidade está associada a características específicas de um bem, como desempenho técnico e durabilidade, já para outras, a qualidade está relacionada à satisfação dos clientes quanto à adequação do produto ao uso. Ainda segundo o mesmo autor a qualidade também pode ser entendida como o atendimento das especificações do produto, em que é avaliada pelo grau de conformidade do produto fabricado com suas especificações de projeto.

Os avanços tecnológicos em diversos setores aumentaram a competitividade das empresas no mercado, desta forma, cada organização deve buscar um diferencial que agregue maior valor aos seus produtos e serviços. A qualidade tornou-se essencial, deve ser buscada em todos os setores e por todos os colaboradores, portanto, a aplicação das ferramentas de qualidade é de extrema importância para aqueles que buscam a qualidade total (SELEME; STADLER, 2010).

Verifica-se que no setor sucroenergético brasileiro há também uma preocupação pela busca da qualidade, com o desenvolvimento e aperfeiçoamento de seus processos produtivos. Devido à grande importância desse setor, que é considerado um dos exemplos mais bem-sucedidos de estratégia integrada de desenvolvimento econômico, selecionou-se uma empresa deste setor para a realização do estudo.

A empresa pesquisada foi fundada em 1980 com a implantação do Proálcool, sendo 100\% nacional. As atividades iniciaram com foco na produção de etanol para abastecimento regional, e com o crescimento do negócio, surgiu a necessidade de expandir seu processamento de cana-de-açúcar com a abertura de mais uma unidade. Hoje, é uma das mais importantes companhias do setor sucroenergético, compreendendo a produção de cana de açúcar, etanol e energia elétrica.

O presente estudo tem como objetivo propor a aplicação de ferramentas da qualidade em uma usina de açúcar e álcool do interior do estado de São Paulo, para auxiliar no controle do processo de moagem e otimizar o percentual de extração de caldo de cana-de-açúcar sobre as causas identificadas como determinantes para o não atingimento de metas.

\section{A PROBLEMÁTICA DO ESTUDO}

Vários fatores influenciam na extração de caldo de cana-de-açúcar em uma usina, os quais destacam-se a qualidade da cana através de sua quantidade de fibras e seus açúcares recuperáveis totais (ATR), as impurezas minerais e vegetais decorrentes da colheita e os equipamentos de preparo e extração (REIN, 2013).

De acordo com a Agência Embrapa de Informação Tecnológica (2013), a eficiência de um terno de moenda pode ser medida por dois parâmetros: capacidade e eficiência de extração. Entende-se por capacidade de um terno de moagem a quantidade de cana moída por unidade de tempo. Já o termo eficiência de extração refere-se à quantidade de sacarose extraída da cana pelas moendas. Alguns fatores que afetam a capacidade de moagem são: preparo da cana, eficiência de alimentação da moenda, tamanho e tipo dos cilindros da moenda e regulagem da bagaceira. 
Na extração por moagem a separação é feita por pressão mecânica dos rolos da moenda sobre um colchão de cana desfibrada, a cana intensamente picada e desfibrada chega às moendas por meio de um alimentador vertical. Cada conjunto de rolos de moenda, montados numa estrutura denominada castelo, constitui um terno de moenda. O número de ternos utilizados no processo de moagem varia de quatro a seis, e cada um deles é formado por quatro cilindros principais (AGÊNCIA EMBRAPA DE INFORMAÇÃO TECNOLÓGICA, 2013).

O problema em foco neste trabalho trata-se dos baixos níveis de extração de açúcares da cana-de-açúcar, a fim de identificar as principais causas para este problema e sugerir ações viáveis para a melhoria dos percentuais de extração de caldo na etapa de moagem, processo inicial considerado como determinante para o bom rendimento de toda a cadeia; uma extração com níveis abaixo do desejável suscita a uma baixa produção da planta.

\section{METODOLOGIA}

A pesquisa deste trabalho consiste em uma pesquisa descritiva por se tratar de um estudo de caso. A pesquisa descritiva exige do investigador uma série de informações sobre o que deseja pesquisar. Este tipo de estudo pretende descrever os fatos e fenômenos de determinada realidade (TRIVINOS, 1987, apud GERHARDT; SILVEIRA, 2008).

Quanto à abordagem a pesquisa classifica-se como qualitativa. Segundo Denzin e Lincoln (apud PEROVANO, 2016, p. 42) a pesquisa qualitativa consiste na interpretação dos dados obtidos do mundo real e natural, desta forma, aproximando mais o pesquisador de seu objeto de pesquisa. Neste método de pesquisa, cabe ao pesquisador determinar o que é relevante diante de tantos dados obtidos na investigação; o foco principal não é medir as variáveis, mas entendê-las.

A problemática abordada no presente estudo é tratada pela aplicação de ferramentas da qualidade de cunho qualitativo. Primeiramente com o brainstorming, em que foram levantadas diversas possíveis causas para os baixos níveis de extração, em seguida adotou-se a ferramenta matriz GUT para a identificação das causas mais prováveis, também foi elaborado o diagrama de Ishikawa para relacionar às causas ao efeito e partir disto serem propostas práticas de melhoria por meio de um plano de ação.

\section{RESULTADOS}

São apresentados a seguir os resultados da aplicação de ferramentas da qualidade baseado em dados e informações não publicáveis coletados com a empresa em estudo.

\section{BRAINSTORMING}

Realiza-se uma sessão de brainstorming com os membros do estudo para o levantamento de possíveis causas acerca do problema, além disso, durante todo período de coleta de dados foram realizadas conversas informais com supervisores da empresa, os quais detêm de maiores conhecimentos técnicos a respeito de formas para a mitigação do problema. Desta forma, são postas as possíveis causas para a ocorrência do problema, enquadradas em 3 grandes blocos: open cells, moenda e impurezas minerais, conforme ilustrado pela Figura 1 a seguir. 
Figura 1. Brainstorming realizado sobre a problemática em estudo.

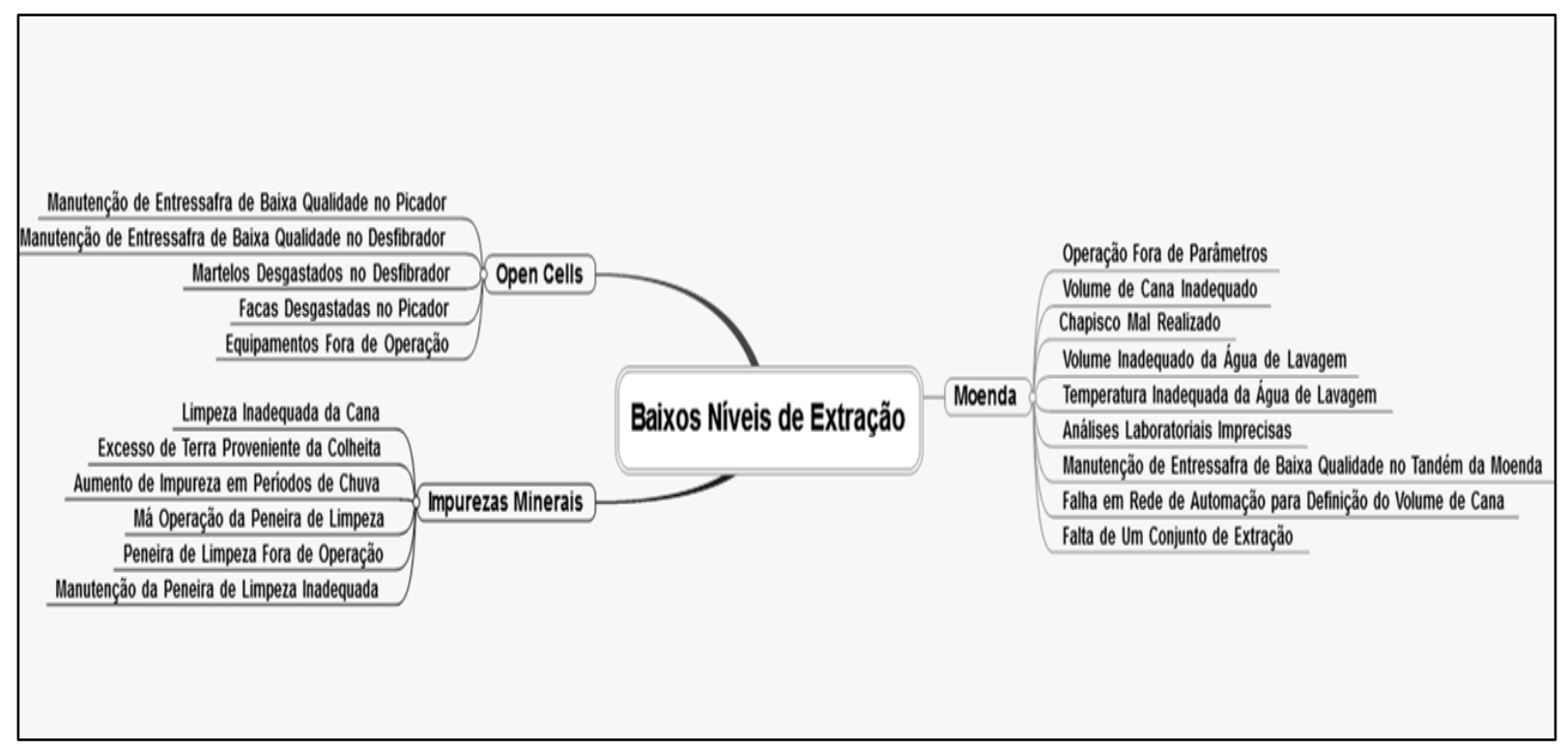

Fonte: Autoria própria.

Na categoria de causas primárias, open cells refere-se à quão abertas estão as células vegetais da cana-de-açúcar após passagem por equipamentos (desfibrador e picador) de preparo, já a moenda trata-se de fatores relacionados ao conjunto de ternos de extração, por fim, impurezas minerais entende-se como sujeiras que veem agregadas à cana-de-açúcar provenientes do corte e da colheita.

\section{MATRIZ GUT}

Aplica-se a matriz GUT para avaliar quais das possíveis causas (secundárias) levantadas do brainstorming são prioritárias para o estudo. A Tabela 1 a seguir apresenta a matriz GUT preenchida com notas de 1 a 5, de acordo com as relevâncias para cada fator: para gravidade (G) a variação é de "sem gravidade" (1) a "extremamente grave" (5); para urgência (U) a variação é de "pode esperar" (1) a "precisa de ação imediata" (5); para tendência (T) a variação é de "não irá mudar" (1) a "agravar rapidamente" (5). 
Tabela 1. Matriz GUT das causas do problema.

\begin{tabular}{|c|c|c|c|c|}
\hline Causas do Problema & Gravidade & Urgência & Tendência & GUT \\
\hline Aumento de impurezas em período de chuva & \begin{tabular}{|l|l}
4 \\
\end{tabular} & 5 & \begin{tabular}{|l|l|l}
4 & \\
\end{tabular} & 80 \\
\hline Manutenção de entressafra de baixa qualidade do tandém da moenda & 5 & 4 & 4 & 80 \\
\hline Martelos desgastados no desfibrador & 3 & 5 & 5 & 75 \\
\hline Facas desgastadas no picador & 3 & 5 & 5 & 75 \\
\hline Operação fora de parâmetros & 5 & 5 & 3 & 75 \\
\hline Manutenção de entressafra de baixa qualidade do picador & 5 & 3 & 4 & 60 \\
\hline Manutenção de entressafra de baixa qualidade do desfibrador & 5 & 3 & 4 & 60 \\
\hline Volume de cana inadequado & 4 & 5 & 3 & 60 \\
\hline Falta de um conjunto de extração & 4 & 3 & 3 & 36 \\
\hline Equipamentos fora de operação & 3 & 3 & 2 & 18 \\
\hline Limpeza inadequada da cana & 2 & 2 & 3 & 12 \\
\hline Chapisco mal realizado & 3 & 2 & 2 & 12 \\
\hline Excesso de terra proveniente da colheita & 3 & 3 & 1 & 9 \\
\hline Volume inadequado da água de lavagem & 3 & 3 & 1 & 9 \\
\hline Análises laboratoriais imprecisas & 3 & 3 & 1 & 9 \\
\hline Temperatura inadequada da água de lavagem & 2 & 2 & 1 & 4 \\
\hline Peneira de limpeza fora de operação & 3 & 1 & 1 & 3 \\
\hline Má operação da peneira de limpeza & 2 & 1 & 1 & 2 \\
\hline Manutenção da peneira de limpeza inadequada & 2 & 1 & 1 & 2 \\
\hline Falha em rede de automação para definição do volume de cana & 1 & 1 & 1 & 1 \\
\hline
\end{tabular}

Fonte: Autoria própria.

Os itens de manutenção de entressafra de baixa qualidade do picador, do desfibrador e do tandém da moenda enquadram-se em um único tópico a partir deste ponto.

As causas que apresentaram pelo menos uma nota de grau 4 em um dos fatores foram selecionadas para a aplicação da ferramenta de diagrama de causa e efeito em sequência.

\section{DIAGRAMA DE CAUSA E EFEITO (ISHIKAWA)}

A partir da matriz GUT foram selecionadas as causas de maior significância para a relação destas com o problema em estudo, conforme ilustrado pela Figura 2.

Figura 2. Diagrama de causa e efeito para o problema de baixo nível de extração.

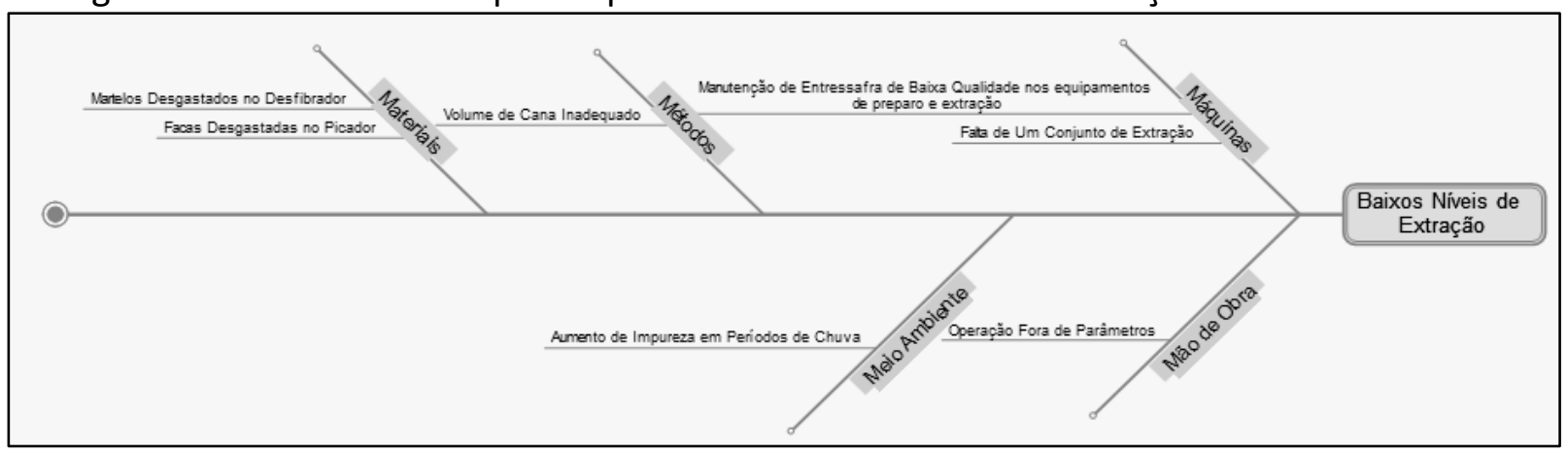

\section{PLANO DE AÇÃO}

Fonte: Autoria própria.

Com base nas informações obtidas do diagrama de Ishikawa foram propostas ações a serem tomadas para a mitigar ou erradicar com os problemas causadores dos baixos níveis de extração por meio da aplicação de plano de ação, apresentado pela Tabela 2 logo abaixo. 
Tabela 2. Plano de ação para as causas dos baixos níveis de extração.

\begin{tabular}{|c|c|c|c|c|c|c|}
\hline \multicolumn{7}{|c|}{ PLANO DE ACÃO } \\
\hline & O QUE & POR QUE & QUEM & ONDE & QUANDO & COMO \\
\hline \multicolumn{7}{|c|}{ MÁQUINAS } \\
\hline $\begin{array}{l}\text { 1. Manutenção de entressafra de } \\
\text { baixa qualidade nos } \\
\text { equipamentos de preparo e } \\
\text { extração }\end{array}$ & $\begin{array}{c}\text { Realizar } \\
\text { manutenção de } \\
\text { boa qualidade } \\
\text { nos } \\
\text { equipamentos } \\
\end{array}$ & $\begin{array}{c}\text { Para aumentar a } \\
\text { confiabilidade e } \\
\text { eficiência dos } \\
\text { equipamentos }\end{array}$ & $\begin{array}{c}\text { Prestador de } \\
\text { serviço externo }\end{array}$ & $\begin{array}{l}\text { Na empresa } \\
\text { terceirizada }\end{array}$ & $\begin{array}{l}\text { Em época de } \\
\text { entressafra }\end{array}$ & $\begin{array}{l}\text { Limpeza, } \\
\text { reforma e troca } \\
\text { de } \\
\text { sobressalentes }\end{array}$ \\
\hline $\begin{array}{l}\text { 2. Falta de um conjunto de } \\
\text { Extração }\end{array}$ & $\begin{array}{c}\text { Instalar o sexto } \\
\text { conjunto de } \\
\text { extração }\end{array}$ & $\begin{array}{c}\text { Para aumentar } \\
\text { os níveis de } \\
\text { extração }\end{array}$ & $\begin{array}{c}\text { Usina e pretador } \\
\text { de serviço } \\
\text { especializado }\end{array}$ & $\begin{array}{c}\text { Setor de } \\
\text { moagem da cana }\end{array}$ & $\begin{array}{l}\text { Em época de } \\
\text { entressafra }\end{array}$ & $\begin{array}{l}\text { Realização do } \\
\text { projeto de } \\
\text { implantação }\end{array}$ \\
\hline \multicolumn{7}{|c|}{ MÉTODOS } \\
\hline 1. Volume de cana inadequado & $\begin{array}{c}\text { Ajustar o volume } \\
\text { de cana }\end{array}$ & $\begin{array}{l}\text { Para aumentar } \\
\text { os níveis de } \\
\text { extração }\end{array}$ & $\begin{array}{l}\text { Operadores da } \\
\text { moenda }\end{array}$ & $\begin{array}{c}\text { Setor de } \\
\text { moagem da cana }\end{array}$ & $\begin{array}{l}\text { Em paradas } \\
\text { programadas }\end{array}$ & $\begin{array}{l}\text { Adequação de } \\
\text { volume } \\
\text { conforme a } \\
\text { moagem/hora } \\
\text { planejada }\end{array}$ \\
\hline \multicolumn{7}{|c|}{ MATERIAIS } \\
\hline $\begin{array}{l}\text { 1. Martelos e facas desgastados } \\
\text { de equipamentos do preparo }\end{array}$ & $\begin{array}{l}\text { Substituição de } \\
\text { peças no tempo } \\
\text { programado }\end{array}$ & $\begin{array}{c}\text { Para garantir } \\
\text { bons níveis de } \\
\text { células abertas } \\
\text { da cana } \\
\end{array}$ & $\begin{array}{l}\text { Operadores da } \\
\text { moenda }\end{array}$ & $\begin{array}{c}\text { Setor de preparo } \\
\text { da cana }\end{array}$ & $\begin{array}{l}\text { Em paradas } \\
\text { programadas }\end{array}$ & $\begin{array}{c}\text { Retirando peças } \\
\text { desgastadas e } \\
\text { substituindo por } \\
\text { novas }\end{array}$ \\
\hline \multicolumn{7}{|c|}{ MÃO DE OBRA } \\
\hline 1. Operação fora de parâmetros & $\begin{array}{l}\text { Melhorar a } \\
\text { operação }\end{array}$ & $\begin{array}{l}\text { Para eliminar } \\
\text { falhas } \\
\text { operacionais }\end{array}$ & $\begin{array}{l}\text { Supervisor de } \\
\text { extração }\end{array}$ & $\begin{array}{c}\text { Setor de preparo } \\
\text { e extração de } \\
\text { caldo }\end{array}$ & Todos os dias & $\begin{array}{c}\text { Aplicação de } \\
\text { ferramentas de } \\
\text { melhoria } \\
\text { contínua }\end{array}$ \\
\hline \multicolumn{7}{|c|}{ MEIO AMBIENTE } \\
\hline $\begin{array}{l}\text { 1. Aumento de impureza em } \\
\text { períodos de chuva }\end{array}$ & $\begin{array}{l}\text { Diminuir } \\
\text { quantidade de } \\
\text { impurezas } \\
\text { minerais }\end{array}$ & $\begin{array}{c}\text { Para aumento de } \\
\text { níveis de } \\
\text { extração e } \\
\text { preservar } \\
\text { máquinas e } \\
\text { equipamentos }\end{array}$ & $\begin{array}{l}\text { Responsáveis } \\
\text { pelas áreas } \\
\text { agrícola e } \\
\text { industrial }\end{array}$ & $\begin{array}{l}\text { Setor } \\
\text { agroindustrial }\end{array}$ & $\begin{array}{l}\text { Geralmente em } \\
\text { períodos pós- } \\
\text { chuva }\end{array}$ & $\begin{array}{l}\text { Postergando o } \\
\text { início da } \\
\text { moagem após } \\
\text { período de } \\
\text { parada pós } \\
\text { chuva }\end{array}$ \\
\hline
\end{tabular}

Fonte: Autoria própria.

\section{DISCUSSÃO}

As ferramentas de caráter qualitativo utilizadas no presente trabalho foram eleitas de acordo com a natureza da problemática em estudo, visto que o problema de baixos níveis de extração de caldo de cana-de-açúcar no processo de moagem da usina já é de habitual conhecimento e comprovada ocorrência dentro da empresa.

Os métodos de qualidade em aplicação mostraram-se satisfatórios na obtenção de resultados, de acordo com às necessidades firmadas pela questão em análise. Por meio da sessão de brainstorming, diversas causas possíveis geradoras do problema foram identificadas, e com a utilização de uma matriz de prioridade tais causas foram filtradas em motivos mais prováveis do problema. Dessa forma, foi praticável a construção do diagrama de Ishikawa para categorizar e relacionar às causas ao efeito, para ao final, justapor dadas informações em um plano de ação sobre: o quê, o porquê, quem, quando, onde e como realizar as devidas propostas de melhoria destacadas na Tabela 2.

\section{CONSIDERAÇÕES FINAIS}

A qualidade é um importante fator de competitividade para as empresas no mercado atual através de utilização de ferramentas e métodos que contribuem para a melhoria de resultados nas organizações. Dentre as principais ferramentas da qualidade optou-se pela aplicação das de cunho qualitativo, para melhor análise do problema em estudo, uma vez que já se conhecia que os baixos níveis de extração de caldo prejudicavam a eficiência do processo.

Com a aplicação da sessão de brainstorming pode-se perceber que várias são as causas geradoras do problema, entretanto, algumas causas se destacaram pelo seu grau de significância para 
a ocorrência dos baixos níveis de extração, conforme foi mostrado pelo uso da matriz GUT. Sendo assim, foi possível propor através do plano de ação melhorias para melhor desempenho do setor de extração de caldo. Se implantados, afirma-se seguramente que tais sugestões trariam benefícios para a empresa.

\section{REFERÊNCIAS}

AGENCIA EMBRAPA DE INFORMAÇÃO TECNOLÓGICA. Extração. 2013. Disponível em: $<$ http://www.agencia.cnptia.embrapa.br/gestor/cana-de-

acucar/arvore/CONTAG01_103_22122006154841.html>. Acesso em: 19 mar. 2017.

BATALHA, M. O. (Organizador). Introdução à engenharia de produção. Rio de Janeiro: Elsevier, 2008.

CARPINETTI, Luiz Cesar Ribeiro. Gestão da qualidade: conceitos e técnicas. 3 ed. São Paulo: Atlas, 2016.

GERHARDT, T. E.; SILVEIRA D. T. Métodos de pesquisa. Rio Grande do Sul: UFRGS, 2008.

MONTGOMERY, D. C. Introdução ao controle estatístico da qualidade. 4. ed. Rio de Janeiro: LTC, 2004.

PEROVANO, D.G. Manual de metodologia de pesquisa científica. Curitiba: InterSaberes, 2016.

REIN, Peter. Engenharia do açúcar de cana. 1. ed. Berlin: Verlag Dr. Albert Bartens KG, 2013.

SELEME, R.; STADLER, H. Controle da qualidade: as ferramentas essenciais. 2. ed. Curitiba: Ibpex, 2010. 